Aletria, Belo Horizonte, v. 28, n. 3, p. 135-148, 2018

\title{
Retórica do caminhar, uma geografia poética
}

\section{The Rhetoric of Walking, a Poetic Geography}

\author{
Gabriel Antunes Ferreira de Almeida \\ Università degli studi di Perugia, Perugia / Itália \\ gboerbon@gmail.com
}

Resumo: Michel de Certeau analisa a arte de guerra com a qual o homem do cotidiano enfrenta as teias pesadas criadas pelas instituições e pelo sistema. O homem é capaz de criar no espaço dado por esses elementos, novos lugares e novos significados. Certeau traça uma história desta relação entre os modos de fazer e os modos de saber. A retórica, alimentada da $\mu \tilde{\eta} \tau \iota \varsigma$, passa a ser uma prática e um lugar teórico capaz de explicar essa dinâmica entre as forças dos mais fortes e dos mais fracos. O caminhar do pedestre nas ruas da cidade é a metáfora por excelência que Michel de Certeau usa para exemplificar a sua teoria das práticas cotidianas.

Palavras-chave: Michel de Certeau; retórica; metis; caminhar; metáfora.

\begin{abstract}
Michel de Certeau analyses the art of war in which people use tactics to confront oppressive institutions and systems. Humans can create new spaces and new meanings in the very establishments that limit and define them. Certeau traces a history of the relationship between modes of doing and modes of knowing. The rhetoric, fed from $\mu \tilde{\eta} \tau \iota \varsigma$, becomes a theoretical place capable of explaining the dynamic between the forces of the strongest and the weakest. The walk of the pedestrian on the streets of the city is the metaphor par excellence that Michel de Certeau uses to exemplify his theory of everyday practices.
\end{abstract}

Keywords: Michel de Certeau; rhetoric; metis; walk; metaphor. 
Lentamente, os representantes que simbolizavam ontem famílias, grupos e ordens saem de cena [...] É o nascimento do número, da democracia, da grande cidade, das administrações, da cibernética. [...] multidão de heróis quantificados que perdem nomes e rostos, tornando-se uma linguagem móvel de cálculo e de racionalidade que não pertence a ninguém. ${ }^{1}$

Um novo uso da escrita surge com a Modernidade, diferentemente daquele da época medieval. Se antes a escrita refletia uma Palavra que se realizava no ato de escutar do crente, na época moderna ela reflete as novas condições culturais, um silêncio desse Outro que não fala mais. Ao olhar as grandes navegações e os atos jurídicos sobre as possessões demoníacas, podemos entender que o novo uso da escrita reflete uma dinâmica onomástica, racional e conquistadora. A racionalidade permeia toda a sociedade e toma conta das relações também fora do laboratório e dos experimentos. Diante desse quadro de dominação promovido pela racionalidade, Certeau olha para algo ignorado nos discursos que analisaram a sociedade. Não existe somente o domínio da rede que tudo envolve, mas existem inúmeras práticas retóricas, exercidas no cotidiano, produtoras de resistências (iremos ver alguns exemplos adiante). Neste artigo, iremos nos concentrar em seu livro L'Invention du quotidien (v. 1, "Arts de faire", principalmente na primeira, segunda e terceira partes) ${ }^{2}$ e, também, usaremos alguns artigos de estudiosos que já se debruçaram sobre este texto com a finalidade de confronto e confirmação de nossas interpretações sobre Certeau.

A finalidade do estudo das práticas cotidianas realizadas pelo homem comum é a demonstração do espaço existente na relação entre

\footnotetext{
1 "Lentamente, rappresentanti che simbolizzavano ieri famiglie, gruppi e ordini escono dalla scena [...] Ė l'avvento del numero, quello della democrazia, della grande città, delle amministrazioni, della cibernetica [...] moltitudine di eroi quantificati che perdono nome e volto divenendo il linguaggio mobile di calcoli e di razionalità che non appartengono a nessuno" (CERTEAU. L'invenzione del quotidiano, p. 25-26, tradução minha).

${ }^{2} \mathrm{O}$ livro L'Invention du quotidien: arts de faire, que inicialmente teve partes publicadas nas revistas Traverses, entre 1975 e 1979, e Esprit, entre 1978 e 1979, foi publicado pela primeira vez na França, em 1980 (Cf. GIARD. Storia di una ricerca, p. XVII). A tradução para o português, intitulada $A$ invenção do cotidiano, teve sua primeira edição lançada em 1994, pela editora Vozes, chegando, em 2014, à $22^{\mathrm{a}}$ edição. Usaremos a versão em italiano que está devidamente indicada nas referências.
} 
aquelas instâncias produtoras de uma cultura ${ }^{3}$ e aqueles que a consomem, e, principalmente, a demonstração de que estes consumidores não são dóceis ou passivos em relação aos produtores. Ou seja, no centro do estudo do livro de Certeau estão as combinações de operações que existem entre estes dois polos (de produção e consumo), principalmente visando dar uma formalidade às ações criativas (os usos criativos) destes sujeitos e grupos de consumidores. Certeau analisa esta relação entre os processos de produção e consumo como campos de força, usando uma dinâmica polemológica na qual o conflito ${ }^{4}$ tem um papel fundamental, pois indica uma fraqueza da racionalidade que pensa em poder controlar tudo. Por isso Certeau usa dois termos, presentes em todo o livro: estratégia e tática. O que marca a divisão entre estas duas práticas é o uso que elas fazem dos "espaços" e o tipo de produção que surge delas.

A estratégia é o cálculo de forças que acontece no momento em que um sujeito (com vontade e poder) se isola em um ambiente. Pressupõe o ambiente interno, circunscrito como "próprio", que funciona como base para a gestão de seus relacionamentos com uma exterioridade que é distinta do lugar "próprio". Este é o exemplo de processo que encontramos na racionalidade política, econômica ou científica. Como características de produção, são racionalidades expansivas e especulativas. Os frutos desse tipo de produção seriam a vitória do espaço, ou seja, o seu controle sobre o tempo; o controle que permite uma prática panóptica, pois

\footnotetext{
${ }^{3}$ Certeau deixa claro que não é somente a cultura a ser estudada através desta dinâmica aprofundada neste artigo. Por isso, esse texto é um marco teórico para vários estudos diferentes.

${ }^{4} \mathrm{O}$ tema do conflito, ainda que em outra vertente, já aparece no estudo de Certeau L'Étranger ou l'union dans la différence, publicado em 1969. Nesses primeiros escritos, Certeau está mais interessado em falar da questão do conflito sob a ótica pessoal, sobre a questão da relação entre o conflito e o limite, além de diferenciar o conflito da violência. O conflito é um meio de resistência, um meio para manter a diferença e resistir à tentação de assimilação (CERTEAU. Lo straniero o l'unione nella differenza, p. 30).

${ }^{5}$ Certeau diferencia lugar e espaço. O primeiro é ligado à estratégia e o segundo à tática. Usaremos aqui os dois termos de forma distinta para nos referirmos sempre às diferentes práticas: como Certeau, empregaremos o termo "espaço", entre aspas (por falta de outro vocábulo), de forma neutra, para indicar o ambiente. A palavra espaço, quando não tiver relação com a prática da tática e for usada sem aspas, será apresentada quando o contexto da frase o deixar claro.
} 
transforma as forças exteriores em objetos que são observados e medidos; e a possibilidade de definir o lugar do poder de saber. ${ }^{6}$

A tática é um cálculo que não obedece às leis do lugar "próprio", como ocorre na estratégia. Como consequência, não define uma fronteira produtora de distinção entre uma exterioridade (um lugar não "próprio") e um lugar "próprio". A tática tem como espaço de ação somente o lugar imposto pelo sujeito que realiza a estratégia (atua num espaço outro). Podemos ainda elencar outras características presentes no texto de Certeau para definir a tática: é o uso da astúcia ligado a uma ocasião em que o sujeito mais fraco se encontra no espaço dado pelo sistema, criado pela estratégia; é a "arte de fazer" dos mais fracos, usando a seu favor a situação imposta pelo sujeito mais forte. ${ }^{7}$ Por isso Certeau faz esta analogia: os sujeitos que realizam as táticas são "[...] inventores de caminhos dentro da floresta da racionalidade funcionalista, os consumidores produzem algo como a imagem dos traçados de que Deligny ${ }^{8}$ fala". ${ }^{9}$

Deixando de lado uma análise mais conceitual, Certeau se lança em uma pesquisa histórica sobre a diferenciação dessas práticas (táticas e estratégias) no decorrer da evolução do pensamento humano. O processo histórico de tentativa de domínio da estratégia sobre as táticas é chamado

\footnotetext{
${ }^{6}$ CERTEAU. L'invenzione del quotidiano, p. 15, 66, 71-72.

${ }^{7}$ CERTEAU. L'invenzione del quotidiano, p. 15, 64, 66.

${ }^{8} \mathrm{Cf}$. DELIGNY. Les vagabonds efficaces et autres récits. O projeto de Deligny começa quando ele funda uma comunidade na França para dar assistência às crianças com autismo e mudas. O objetivo era dar voz a esses dois grupos de crianças que não conseguiam se expressar com a linguagem oral. O processo de "escutar" esses diversos tipos de "vozes" e linguagens acontecia através de uma cartografia particular. $O$ autor sobrepunha um papel vegetal, que continha os traçados resultantes dos deslocamentos das crianças, dos objetos com os quais essas crianças tinham relação e os deslocamentos dos percursos feitos pelos adultos, à planta baixa das áreas de convivência dessa comunidade (AMARA. Dopo il disastro del linguaggio: Le lignes d'erre di Fernand Deligny, p. 187). Para designar essa linguagem que se move no espaço solto do papel, Deligny usa o termo ligne d'erre. Amara explica que a escolha da denominação erre se dá por um jogo de palavras para evitar precisar o tempo e o sujeito que atua ( $e u$ ou $t u)$, e para não fechar em uma palavra os traços sem fim ao utilizar a palavra errance (AMARA. Dopo il disastro del linguaggio: Le lignes d'erre di Fernand Deligny, p. 191).

9 “" $[. .$.$] inventori di sentieri nella giungle della razionalità funzionalista, i consumatori$ producono qualcosa che assume la figura dei "tracciati' di cui parla Delegny" (CERTEAU. L'invenzione del quotidiano, p. 69, tradução minha).
} 
por Certeau de etnologização das artes de fazer. Certeau circunscreve tal processo entre as artes práticas e as ciências. A primeira designa os modos de fazer através da figura do artista-artesão, a segunda é a nova configuração do saber racional realizada pelo cientista. É uma divisão que nasce da diferenciação de operação, ou seja, a primeira operará em modo não discursivo e a segunda. em modo discursivo. ${ }^{10}$

Ao longo da história houve tentativas, afirma Certeau, de aproximar estas duas operações diversas para obtenção, é claro, de domínio pelas operações discursivas das não discursivas. O exemplo mais interessante é de Wolff, ${ }^{11}$ que, no ano de 1740 , escreve a respeito da existência de um homem definido como engenheiro com a capacidade de reunir tanto a arte quanto a ciência, um mediador entre os dois tipos de processos, localizado entre o homem do teorema e o homem da arte. Wolff representa o pensamento iluminista, refletindo a ideia da existência de um saber inscrito já nas artes práticas, mas ainda não esclarecido, sendo necessária a ciência com a sua linguagem racional para a leitura desse saber não discursivo. Mas, aponta Certeau, o que pode ser conhecido historicamente no desenvolvimento dessa linguagem racional na engenharia, ocorrido posteriormente ao iluminismo, foi a subtração, pelo uso das máquinas, das prestações individuais que existiam nas artes de fazer, pois as máquinas constituíram combinações bem mais controláveis do que o homem, e, como consequência, elas destituíram a arte de fazer daquilo que a articulava objetivamente ao seu "fazer": as máquinas subordinadas a uma tecnologia destacam o "fazer" do desempenho individual, reduzem o saber fazer a um espaço folclórico ou da vida privada. Este saber "fazer" assume características de intuição e sem referência ao sujeito como proprietário, mas como locatário do saber. ${ }^{12}$ Pensemos, por exemplo, no trabalho de alfaiataria. Um terno feito à mão pode demorar certo tempo para ficar pronto. É um trabalho que expressa individualidade, pois as medidas são exclusivas daquele que vestirá a roupa, da posição única e irrepetível das linhas que tecem o tecido; a escolha do ponto caseado ou ponto de

\footnotetext{
${ }^{10}$ CERTEAU. L'invenzione del quotidiano, p. 110.

${ }^{11}$ CERTEAU. L'invenzione del quotidiano, p. 115. Certeau, na nota de número 14, indica o prefácio escrito por Christian Wolff na obra de Belidor, Architecture hydraulique, seguindo a indicação presente em "Les Commencements de la technologie", de Jacques Guillerme e Jan Sebestik.

${ }^{12}$ CERTEAU. L'invenzione del quotidiano, p. 117.
} 
alinhavo para cada dobra da peça. É o trabalho do homem que deve engenhar soluções únicas para cada um de seus clientes. Por outro lado, a produção à máquina cortará alguns ternos de tamanhos standards, para serem vendidos em lojas de departamento.

No que se refere à relação entre táticas e estratégias na história contemporânea, Certeau acredita que o comprometimento do indivíduo diminui paralelamente ao aumento tecnocrático; logo, não resta a dúvida que a astúcia da tática seja uma solução para os problemas solevados. ${ }^{13}$ Há, segundo o autor, uma mudança tanto nas táticas quanto nas estratégias que lidam com a generalização e expansão através das inúmeras malhas do sistema da racionalidade tecnocrática. As táticas, antes reguladas por unidades locais, são mais fragmentadas e proliferadas, enquanto as estratégicas não encontram mais a externalidade, pois a formação do lugar "próprio" é totalizante. Certeau aponta para a possibilidade de um desenvolvimento daquilo que ele chama de sociedade cibernética, com movimentos brownianos ${ }^{14}$ de táticas, ou seja, um espaço no qual há uma enorme e incontrolável manipulação aleatória no interior de uma rede homogênea muito densa. ${ }^{15}$

Como já visto, Certeau definirá as táticas cotidianas, nascidas de dentro do sistema e realizadas pelos homens comuns, como uma manipulação; práticas acostadas à retórica e que oferecem um repertório de figuras típicas à análise dos modos de fazer cotidiano. Os sofistas terão um espaço privilegiado: ${ }^{16}$

a sua [tática] dialética poderá ser iluminada pela antiga arte dos sofistas. [...] Aristóteles [...] cita uma fórmula que, precisando a intenção da sofística, pode finalmente definir a tática como nós a

\footnotetext{
${ }^{13}$ CERTEAU. L'invenzione del quotidiano, p. 21.

${ }^{14}$ Robert Brown, em 1828, observa as partículas em suspensão como um movimento randômico e não consegue indicar a direção que essas partículas seguiriam em um próximo momento. Einstein consegue elucidar a causa desse fenômeno em 1905. São movimentos presentes tanto em nível micro como macroscópico (em ordem de grandeza astronômica) (SALINAS. Einstein e a teoria do movimento browniano, p. 263; SILVA; LIMA. Quatro abordagens para o movimento browniano, p. 25-26).

${ }^{15}$ CERTEAU. L'invenzione del quotidiano, p. 77-78.

${ }^{16}$ CERTEAU. L'invenzione del quotidiano, p. 17.
} 
pensamos: se trata, como dizia Górgias, ${ }^{17}$ de "tornar mais forte o argumento mais fraco". ${ }^{18}$

Retórica e táticas têm a mesma dinâmica. Através de astúcia e engenho, elas constroem sentidos "próprios" a partir do cenário que lhes foi dado. As figuras e artifícios da retórica são usados para distorcer, através do uso da linguagem, a propriedade dos termos que a gramática defende; essa é a mesma dinâmica presente nas táticas. ${ }^{19}$ Mesmo não se referindo a um sistema de linguagem, os mesmos artifícios da retórica (metáforas, analogias, elipses) podem ser vistos como estilo de resistência dos mais fracos.

As táticas operam através do que os gregos chamavam de $\mu \tilde{\eta} \tau \iota \varsigma$. $\mathrm{O}$ artigo escrito por Dolmage ${ }^{20}$ ajuda a entender melhor o termo grego. $\mathrm{O}$ autor indica que a $\mu \tilde{\eta} \tau \iota \varsigma$ se aproxima dos significados de uma inteligência que demonstra destreza, é adaptativa e incorporada. ${ }^{21}$ Dolmage repropõe a sugestão de Lois Bragg, ${ }^{22}$ indicando, no mundo antigo, a $\mu \tilde{\eta} \tau \iota \varsigma$ como retórica contraposta ao progresso linear do pensamento racional, já que ela tece um ziguezague. ${ }^{23} \mathrm{O}$ autor cita - como também o faz Certeau $-{ }^{24}$ o trabalho de Marcel Detienne e Jean-Pierre Vernant, Les Ruses de l'intelligence: la mètis des Grecs, que definem a $\mu \tilde{\eta} \tau \imath \varsigma$ como

${ }^{17}$ Na nota explicativa de número 175, na obra Retórica, é-nos sugerido que Aristóteles atribui essa máxima a Protágoras. Parece ser um erro de Certeau (Cf. ARISTÓTELES. Retórica, p. 234).

18 "la sua dialettica potrà essere illuminata dall'antica arte della sofistica [...] Aristotele [...] egli cita una formula che, precisando l'intento della sofistica, può finalmente definire la tattica come noi qui la intendiamo: si tratta, come diceva Gorgia, di 'rendere più forte il discorso più debole"' (CERTEAU. L'invenzione del quotidiano, p. 74, tradução minha). ${ }^{19}$ CERTEAU. L'invenzione del quotidiano, p. 75-76.

${ }^{20}$ Cf. DOLMAGE. Metis, Mêtis, Mestiza, Medusa: Retorical Bodies across Rhetorical Traditions.

${ }^{21}$ DOLMAGE. Metis, Mêtis, Mestiza, Medusa: Rhetorical Bodies across Rhetorical Traditions, p. 5.

${ }^{22}$ Cf. BRAGG. Oedipus Borealis: The Aberrant Body In Old Icelandic Myth and Saga.

${ }^{23}$ DOLMAGE. Metis, Mêtis, Mestiza, Medusa: Rhetorical Bodies across Rhetorical Traditions, p. 5.

${ }^{24}$ A primeira referência feita por Certeau se encontra na nota de número 9, quando cita alguns autores que trabalharam com as teorias das práticas, dos ritos e bricolagens, das manipulações de espaço e ativação de rede (Cf. CERTEAU. L'invenzione del quotidiano, p. 11). 
uma inteligência complexa, um corpo coerente de atitude mental e comportamento intelectual:

uma forma de inteligência sempre imersa na prática, na qual se combinam a perspicácia, a sagacidade, a previsão, a ductilidade, a dissimulação, a capacidade de desemaranhar-se, a atenção vigilante, o sentido de oportunidade, a habilidade diversa, a experiência de longa duração. ${ }^{25}$

Certeau $^{26}$ identifica três elementos com os quais a $\mu \tilde{\eta} \tau \iota \varsigma$ se relaciona

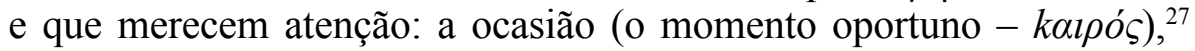
a simulação (multiplicação de máscaras e metáforas) e uma paradoxal invisibilidade (no seu próprio ato desaparece sem uma imagem de si). Os provérbios ou enunciações proverbiais são fundados sobre a $\mu \tilde{\eta} \tau \iota \varsigma$, sobre o senso prático. Podemos colocá-los como atos locutórios, quando um falante se apropria da língua em uma situação particular de troca ou contrato. Esta dinâmica acontece não somente no campo da língua, mas também na rede das práticas sociais. $\mathrm{O}$ ato locutório é ligado às circunstâncias, enquanto o discurso, não. O ato locutório é marcado pelo uso. ${ }^{28}$

Outro elemento que contribui para enfrentar essa rede de dominação, lembrado por Simone Lucido, ${ }^{29}$ é o imprevisto como uma inscrição no tempo não homogêneo que separa e conecta, no lapsus como prontidão a indicar a lacuna do sistema de produção. Certeau lembra em seu texto

25 “une forme d'intelligence toujours immergée dans la pratique dans laquelle ils combinent la perspicacité, sagacité, prévoyance, ductilité, dissimulation, capacité à se démonter, attention vigilante, le sens de l'opportunité, la capacité diversifiée, l'expérience durable" (DETIENNE; VERNANT. Les ruses de l'intelligence: la mètis des Grecs, p.9-10, tradução minha).

${ }^{26}$ CERTEAU. L'invenzione del quotidiano, p.130-131.

${ }^{27}$ Não é o caso de aprofundar aqui a interessante relação que Certeau faz entre a memória no seu sentido antigo, como presença da pluralidade do tempo, que tanto é instruída por uma multiplicidade de eventos (passados) como é capaz de pensar em inúmeras estradas para o futuro; e a memória como um recurso invisível, que permanece escondida até

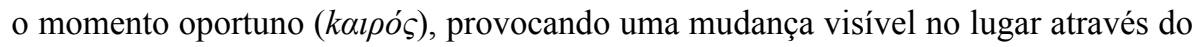
estabelecimento de uma fratura instauradora (CERTEAU. L'invenzione del quotidiano, p. 131-140). Para entender melhor o conceito de fratura instauradora em Certeau, ver CERTEAU. La Rupture instauratrice ou le christianisme dans la culture contemporaine. ${ }^{28}$ CERTEAU. L'invenzione del quotidiano, p. 49-53.

${ }^{29}$ LUCIDO. "Nothing for us without us". Spazio del progetto e democrazia, p. 44. 
que o imprevisto é um tempo acidentado, é uma narrativa indeterminada, articulada por metáforas e lugares estratificados, distanciando-se totalmente do império da evidência na tecnocracia funcionalista. ${ }^{30}$

Certeau traz alguns exemplos para comprovar essa normatividade das práticas táticas sobre as quais está discorrendo, como é o caso da cultura popular e seu modo de utilizar os sistemas impostos, constituindo um tipo de resistência. Os modos de utilização criam margem para um jogo entre forças desiguais. Esses indivíduos ou grupos mais fracos "recriam incessantemente espaços de opacidade e ambiguidade - lugares de sombra e de astúcias - no universo da transparência tecnocrática". ${ }^{31}$ Podemos encontrar a mesma dinâmica nos trabalhadores astutos que recolhem materiais descartados nas fábricas em que trabalham para criar algum produto que, tantas vezes, é destinado ao seu círculo familiar, exercitando a prática do "dom". Certeau cita algumas características presentes nesta dinâmica: exercem uma economia da "dádiva", uma estética de truques e uma ética da tenacidade..$^{32}$

Dentre os exemplos que o leitor poderá encontrar ao longo da leitura do texto de Michel de Certeau nos aprofundaremos em um: o caminhar na cidade como retórica podítica. ${ }^{33}$ Certeau, em certo momento, fala da cidade como exemplo para os seus estudos de práticas cotidianas. ${ }^{34}$ Quando olhamos a cidade de fora, distantes da realidade dela, com uma visão panorâmica (o exemplo parte da observação de Nova Iorque do alto do World Trade Center), tal olhar significa a nossa subtração à cidade e representa a ficção do saber, ou seja, existe ficção quando o saber consiste em somente ter esta visão onipresente, desdenhando e esquecendo as táticas cotidianas. ${ }^{35}$ A cidade que se instaura nesse tipo de discurso, distante da realidade, articula-se em três momentos (momentos que recordarão perfeitamente o uso que a estratégia faz da construção do

\footnotetext{
${ }^{30}$ CERTEAU. L'invenzione del quotidiano, p. 296.

31 “[...] ricrea incessantemente opacità e ambiguità - luoghi d'ombre e di astuzie nell'universo della trasparenza tecnocratica" (CERTEAU. L'invenzione del quotidiano, p. 49, tradução minha).

${ }^{32}$ CERTEAU. L'invenzione del quotidiano, p. 59-60.

${ }^{33}$ Podítica vem da palavra $\pi o ́ \delta l$ (podi) para referir-se ao pé.

${ }^{34}$ Dosse chama a atenção para o fato de que Certeau naquela época não apareceu dentro dos grandes debates do urbanismo com o seu texto sobre a cidade (Cf. DOSSE. O espaço habitado segundo Michel de Certeau, p. 89).

${ }^{35}$ CERTEAU. L'invenzione del quotidiano, p. 144-145.
} 
lugar): produção do lugar próprio, através de uma organização racional do espaço; substituição das resistências que derivam das práticas cotidianas por uma estratégia científica que dê conta de todos os dados; e, por último, a cidade que se cria como sujeito totalizante. ${ }^{36}$

Uma das táticas presentes na cidade é o caminhar, que se institui como espaço de enunciação, da mesma forma que ocorre com o speech act na linguagem. Há três pontos nos quais podemos nos embasar, segundo Certeau, para fazer tal afirmação: o caminhar é um processo de apropriação da geografia por aquele que pratica o ato de caminhar (assim como o locutor e a apropriação para si da língua); é uma realização espacial do lugar (assim como o speech act é a realização sonora da língua); e estabelece relações de posição diferenciadas, contratos pragmáticos (assim como a enunciação verbal é contrato entre interlocutores). ${ }^{37} \mathrm{O}$ pedestre dentro da cidade pode modificá-la, encontrando novas possibilidades, bem como novos atalhos, ou mesmo evitando alguns percursos. Cria descontinuidades dentro de um espaço no qual se imagina a homogeneidade.

"Existe uma retórica do caminhar. A arte de 'elaborar' frases tem como equivalente uma arte de inventar percursos", ${ }^{38}$ pois tanto o caminhar como a linguagem possuem, para Certeau, um estilo (indicador da singularidade linguística de um homem) e um uso (um fenômeno social que remete a um sistema de comunicação). $\mathrm{O}$ ato de inventar percursos - ou o uso da retórica - está centrado na presença dos tropos ou desvios de sentido. ${ }^{39}$ Certeau, fazendo referência ao trabalho iniciado por Augoyard, ${ }^{40}$ indica as duas figuras estilísticas que Augoyard aponta como sendo usadas pelos caminhantes: a sinédoque e o assíndeto. Uma aumenta o detalhe em função do conjunto (como designar uma parte do parque visitado pelo parque inteiro), a outra suprime os termos de ligação

\footnotetext{
${ }^{36}$ CERTEAU. L'invenzione del quotidiano, p. 147-148.

${ }^{37}$ CERTEAU. L'invenzione del quotidiano, p. 151.

${ }^{38}$ CERTEAU. L'invenzione del quotidiano, p. 154.

${ }^{39}$ Alguns exemplos: metáfora, metonímia, catacrese, hipérbole, antonomásia, elipse, etc. ${ }^{40} \mathrm{Cf}$. AUGOYARD. Pas à pas. Essai sur le cheminement en milieu urbain. Dosse conta a história de quando Certeau recusou o convite para prefaciar o livro de Augoyard, com a justificativa de aquele ser um livro sem necessidade de prefácio. Foi um livro muito importante para Certeau, pois trabalhava essa formalização dos modos de apropriação do lugar urbano pelo caminhante (Cf. DOSSE. O espaço habitado segundo Michel de Certeau, p. 90).
} 
(uma caminhada não contendo a totalidade do caminho percorrido, salta partes e ligações). Assim, dos nomes próprios encontrados na cidade (nomes de ruas, praças) surgem novos significados originários desse caminhar, que Certeau chama de uma segunda geografia, uma geografia poética, pairante como neblina sobre a geografia literal. ${ }^{41}$

Através da ampliação, do encolhimento e da fragmentação, por obra da retórica, cria-se um fraseado espacial de tipo antológico (composto de citações justapostas) e elíptico (feito de vazio, lapsus). Ao sistema tecnológico de um espaço coerente e totalizador, "ligado" e simultâneo, as figuras podológicas substituem percursos que têm a estrutura do mito, quando entendemos o mito como um discurso relativo ao lugar/não lugar (origem) da existência concreta. ${ }^{42}$

A mesma dinâmica apresentada na retórica do caminhar, entendida como ato de relatar um espaço (toda narrativa é uma história de viagem), é reforçada pelos estudos de Linde e Labov, ${ }^{43}$ que Certeau usa para dar início a um excursus histórico sobre o problema da fabricação dos mapas. Linde e Labov definiram separadamente o "mapa" do "percurso" pelas operações efetuadas distintamente neles. O mapa retém operações ligadas ao "ver" (é conhecer a ordem do lugar), enquanto o percurso é ligado às operações de "andar" (ou seja, ações espaciais). São definições que até recebem críticas de Certeau, ${ }^{44}$ mas são importantes para entendermos a

${ }^{41}$ CERTEAU. L'invenzione del quotidiano, p. 160.

42 "E attraverso ingrandimenti, rimpicciolimenti e frammentazioni, ad opera della retorica, si crea un fraseggio spaziale di tipo antologico (composto di citazioni giustapposte) ed ellittico (fatto di vuoti, lapsus, allusioni). Al sistema tecnologico di uno spazio coerente e totalizzatore, 'legato' e simultaneo, le figure podistiche sostituiscono percorsi che hanno la struttura del mito, qualora per mito s'intenda un discorso relativo al luogo/non-luogo (origine) dell'esistenza concreta" (CERTEAU. L'invenzione del quotidiano, p. 157, tradução minha).

${ }^{43} \mathrm{Cf}$. LINDE; LABOV, Spatial Networks as a Site for the Study of Language and Thought. ${ }^{44}$ As críticas são ligadas à ideia de que o fazer (as ações espaciais) também permitem um "ver". Certeau não está muito ligado à questão da forma e à consequente divisão com a qual Linde e Labov trabalharam, mas sim às interações nesse cenário do lugar que permite o caminhar, ou seja, o caminhar está marcado pelo lugar, há sempre uma relação entre esses dois processos. 
existência de uma diferença entre o mapa e percurso. ${ }^{45}$ Certeau informa que no Medievo os mapas eram como diários de viagem para serem usados pelos peregrinos, indicando lugares para descansar, trilhas a serem percorridas, caminhos a serem evitados, ou seja, uma narração do percurso feito. Já com a introdução do discurso científico moderno (século XV-XVII), começa-se a notar uma diferença nos mapas, que se distanciam do estilo de narração do percurso. Certeau chama de "colonização do espaço" essa dinâmica de tom totalizante instaurada nos mapas, que os desvincula das ações narrativas que os produzem, apaga os sujeitos que um dia passaram por aquele território e o descreveram. Assim, os mapas são constituídos como lugares para expor os produtos do saber que decorrem desse novo exercício da geografia, como ocorre no urbanismo e na retórica do caminhar.

A grande novidade percebida nos textos de Certeau é a sua tentativa de formalizar essas práticas de resistência que existem dentro de um sistema. O uso, na verdade, também é um tipo de produção. Isso aceito, a análise passa a ser feita através de uma visão de forças que estão em relação polemológica. Existem aquelas mais fortes e as mais fracas. E isso não quer dizer inércia destas últimas, mas um estilo diferente de manutenção da resistência. O respiro que as táticas ganham com seu paralelismo com a retórica deveria ser motivo de um estudo muito mais aprofundado que este. Teria ainda espaço a retórica podítica como modo de uso do espaço nestes tempo de avançada tecnologia? Ou, teríamos ainda a liberdade de imaginar um espaço de resistência? O que nos fica de certeza é o respiro que os nossos passos possam ainda narrar alguma história secreta, de apropriação e novos significados.

Na Atenas de hoje, os transportes públicos são chamados de metaphorai. Para ir ao trabalho ou retornar para casa, pegase uma "metáfora" - um ônibus ou um trem. As narrativas poderiam também receber esse mesmo belo nome: a cada dia elas atravessam e organizam os lugares; elas os selecionam e os conectam [...]. São, então, percursos de espaços. ${ }^{46}$

\footnotetext{
${ }^{45}$ CERTEAU. L'invenzione del quotidiano, p. 177-179.

46 "Nell'Atene di oggi, i trasporti pubblici si chiamano metaphorai. Per andare al lavoro o rientrare a casa, si prende una 'metafora' - un autobus o un treno. I racconti potrebbero portare anch'essi questo bel nome: ogni giorno, attraversano e organizzano dei luoghi; li selezionano e li collegano fra loro [...]. Sono dunque percorsi di spazi." (CERTEAU. L'invenzione del quotidiano, p. 173, tradução minha).
} 


\section{Referências}

AMARA, Lucia. Dopo il disastro del linguaggio: Le lignes d'erre di Fernand Deligny. La Deleuziana, n. 3, p.185-208, 2016.

ARISTÓTELES. Retórica. Tradução e notas de Manuel Alexandre Júnior, Paulo Farmhouse Alberto e Abel do Nascimento Pena. 2. ed. Lisboa: Imprensa Nacional-Casa da Moeda, 2005.

AUGOYARD, Jean François. Pas à pas. Essai sur le cheminement en milieu urbain. Paris: Seuil, 1979.

BRAGG, Lois. Oedipus Borealis: The Aberrant Body In Old Icelandic Myth and Saga. Rutherford: Fairleigh Dickinson Up, 2004.

CERTEAU, Michel de. L'invenzione del quotidiano. Roma: Edizioni Lavoro, 2001.

CERTEAU, Michel de. La rupture instauratrice ou le christianisme dans la culture contemporaine. Esprit, Paris, v. 6, n. 404, p. 1177-1214, 1971.

CERTEAU, Michel de. Lo straniero o l'unione nella differenza. Milano: Vita e Pensiero, 2010.

DELIGNY, Fernand. Les vagabonds efficaces et autres récits. Paris: Maspéro, 1970.

DETIENNE, Marcel; VERNANT, Jean-Pierre. Les ruses de l'intelligence: la mètis des Grecs. Paris: Flammarion, 1974.

DOLMAGE, Jay. Metis, Mêtis, Mestiza, Medusa: Rhetorical Bodies across Rhetorical Traditions. RhetoricReview, v. 28, n. 1, p. 1-28, jan. 2009.

DOSSE, François. O espaço habitado segundo Michel de Certeau. Tradução de Giovanni Ferreira Pitillo. Artcultura, Uberlândia, v. 15, n. 27, p. 85-96, 2013.

GIARD, Luce. Storia di una ricerca. In: CERTEAU, Michel de (Org.). L'invenzione del quotidiano. Roma: Edizioni Lavoro, 2001. p. XVII-XL. GUILLERME, Jacques; SEBESTIK, Jan. Les commencements de la technologie. Thalès, Paris, v. 12, p. 1-72, 1966. 
LINDE, Charlotte; LABOV, William. Spatial Networks as a Site for the Study of Language and Thought. Language, v. 51, n. 4, p. 924-939, dez. 1975. Disponível em: <https://www.jstor.org/stable/pdf/412701.pdf>. Acesso em: 15 dez. 2017.

LUCIDO, Simone. "Nothing for us without us". Spazio del progetto e democrazia. In: RICCIO, Franco (Org.). Spazi eccentrici: Mappe del molteplice sociale. Pisa: Bfs, 2003. p. 35-51.

MARKS, John. Certeau and Foucault: the other and pluralism. Paragraph, Edinburgh, v. 22, n. 2, p. 118-132, 1999.

SALINAS, Silvio. Einstein e a teoria do movimento browniano. Revista Brasileira de Ensino de Física, São Paulo, v. 27, n. 2, p. 263-269, 2005.

SILVA, João Maria da; LIMA, Jose Ademir Sales de. Quatro abordagens para o movimento browniano. Revista Brasileira de Ensino de Física, São Paulo, v. 29, n. 1, p. 25-335, 2007.

Recebido em: 14 de janeiro de 2018.

Aprovado em: 17 de maio de 2018. 